\title{
Biofilm Production by Various Candida Species Isolated From Various Clinical Specimens
}

\author{
Rakesh Kumar Mukhia ${ }^{1}$, Dr. A. D. Urhekar ${ }^{2}$ \\ ${ }^{1}$ PhD Scholar, Microbiology Department, MGM Medical College \& Hospital, Kamothe, Sec-18, Navi Mumbai - 410209 \\ ${ }^{2}$ Professor \& HOD, Microbiology Department, MGM Medical College \& Hospital, Navi Mumbai
}

\begin{abstract}
Background: Candida is one of the most frequently encountered opportunistic fungi that cause severe infection in humans. Incidence of candidiasis is increasing worldwide. The ability of Candida albicans to form biofilms and adhere to host tissues and biomaterial surfaces is an important factor in its pathogenesis. One of the main characteristics of biofilms is their resistant to broadspectrum anti-microbial drugs. Biofilm formation can act as a reservoir of agents, allow co-infection with other pathogens. The aim of the study was to know the biofilm formation by various Candida species isolated from various clinical specimens. The study was carried out over a period of 1 year from January 2015 to December 2015 at the Department of Microbiology, MGM Medical College and Hospital, Kamothe, Navi Mumbai. A total 100 candida strains were isolated from various clinical specimens. Speciation of candida was done by standard yeast identification protocol and Hichrom Candida agar. Biofilm formation was detected by tube method and microtitre plate method. Out of total 100 candida strains studied, biofilm production was seen in 58/100 (58\%) isolates by microtitre plate method. While comparing tube method of biofilm production with microtitre plate method, microtitre plate method detected 5 more biofilm producers than tube method. Conclusion: Candida has certain species which have the capability to produce high grade of biofilm and others which produce low grade of biofilms. We can conclude that microtitre plate assay is seen to be the most sensitive and specific method to detect the biofilm production as compared to tube method.
\end{abstract}

Keywords: Candida species; Biofilm production

\section{Introduction}

Nosocomial infections due to Candida species have increased significantly during the past three decades. Use of a wide range of biomaterial instruments (urinary and indwelling vascular catheters, denture appliances, orthopaedic prostheses and heart valves) in clinical practice accelerates infection by Candida species ${ }^{(1-4)}$. In addition, Nosocomial Candida infections are more prevalent among immune compromised individuals and those with a history of diabetes, malignancy, neutropenia, cancer chemotherapy, organ transplantation, hemodialysis, use of broad-spectrum antimicrobial agents and prolonged hospitalization ${ }^{(5-9)}$. Candiduria, vulvovaginal candidiasis and oral candidiasis are the most important forms of the disease. Candida albicans is still considered as the major etiologic agent in candidiasis and several factors are associated with its pathogenesis. The ability of $C$. albicans to form biofilms and adhere to host tissues and biomaterial surfaces is an important pathogenesis factor ${ }^{(10,11)}$. Biofilm formation can act as a reservoir of agents, allow co-infection with other pathogens, promote persistence of infection and increase mortality ${ }^{(12,13)}$. One of the main characteristics of biofilms is their resistance to broad-spectrum anti-microbial drugs ${ }^{(11,}$ 14, 15). Several studies have shown that sessile yeasts (biofilm) are more resistant to amphotericin B, fluconazole, azoles, and echinocandins when compared to planktonic cells ${ }^{(5,11,14)}$.

\section{Materials \& Methods}

The study was carried out over a period of 1 year (January 2015 to December 2015) at the Department of Microbiology, MGM Medical College \& Hospital, Kamothe, Navi Mumbai. Various Clinical specimens were taken from Patient attending M.G.M. Medical College \& hospital. All chronic purulent exudates were studied for bacterial and fungal growth. Specimens which do not show any pus cells were excluded from further studies. Total 1152 Clinical specimens were taken for this study out of which 100 Candida strains were isolated.

\section{Ethical Clearance:}

The study was cleared by institutional ethics committee of MGM Institute of Health Sciences, Navi Mumbai and written consent from the patients was taken prior to collection of samples.

\section{Samples collection \& processing:}

Various clinical samples like Urine, Stool, Vaginal swabs, Sputum, Throat swab, Endotracheal tube, Skin scrapings, Nail clippings, Eye swabs, Ear swabs, Wounds \& Pus samples were collected in a sterile, properly labelled container with aseptic precautions. The various clinical samples were collected and processed as per the standard microbiological procedures.

\section{Organisms Identification:}

All samples were screened for budding yeast like cells with the help of Gram stain, 10\% KOH, and Specimens were culture on Sabourad's Dextrose Agar with chloramphenicol and Hichrome candida agar, \& incubated at $37^{\circ} \mathrm{C}$ for 48 hours. Growth was then processed for gram staining. Gram positive budding yeast cells with or without pseudohyphae were considered as Candida species. Speciation of Candida was done by germ tube test, carbohydrate fermentation \& assimilation test, colony colour on Hichrom Candida agar and microscopic morphology on corn meal agar \& $45^{\circ} \mathrm{C}$ thermo-tolerance tests. ${ }^{(16)}$

Biofilm Formation: Biofilm formation was detected by two methods as described below. 


\section{International Journal of Science and Research (IJSR) \\ ISSN (Online): 2319-7064}

Index Copernicus Value (2013): 6.14 | Impact Factor (2015): 6.391

Microtitre plate method: Biofilm formation was also determined using preseterilized polystyrene 96-well microplates (Himedia, India) (as described by Yigit $\mathrm{N}$ et al. ${ }^{(17)}$ ). For each isolate, a suspension from an overnight culture on SDA was prepared in sterile distilled water and adjusted to $1 \mathrm{McFarland}$. Each well of the microplate was filled with $180 \mu \mathrm{l}$ of Sabouraud dextrose broth (SDB) (Himedia, India) supplement with $8 \%$ glucose and then $20 \mu \mathrm{l}$ of the standard suspension of tested isolates was inoculated. Microplates were covered with lids and incubated at $35^{\circ} \mathrm{C}$ for 24 hours. The medium in wells was removed and washed three times with sterile phosphate buffer solution (PBS). Microplates were stained with $1 \%$ Safranin for 5 minutes and then percentage transmittance (\% T) was read at $630 \mathrm{~nm}$ by an Elisa reader. All tests were done in duplicates and means were calculated. Finally, adherent biofilm layers were scored as either negative; weak $(+)$ (percentage transmittance $(\% \mathrm{~T}$ $\leq 20))$; moderate, $(++)(\% \mathrm{~T}=20-35)$; strong $(+++)(\% \mathrm{~T}=$ $36-50)$ and very strong $(++++)(\% \mathrm{~T} \geq 50)$.

Tube method: Biofilms was assessed by the tube method (as described by Christensen G.D. et al. ${ }^{(18)}$ and Gokce G et $\left.a l .{ }^{(19)}\right)$. Colonies of Candida species from Sabouraud's dextrose agar were inoculated in saline and incubated overnight at $37^{\circ} \mathrm{C}$. $0.5 \mathrm{ml}$ of this saline suspension was added into screw capped conical polystyrene tubes containing $5 \mathrm{~mL}$ of Sabouraud's dextrose broth supplemented with glucose (final concentration of $8 \%$ ). The tubes were incubated at $35^{\circ} \mathrm{C}$ for $48 \mathrm{~h}$ without agitation. After incubation the broth from the tubes was aspirated gently using Pasteur pipette. The tubes were washed twice with distilled water and stained with $1 \%$ safranine. The stain was decanted after $10 \mathrm{~min}$. The tubes were rinsed with distilled water to remove excess stain. Presence of visible adherent film on the wall and at the bottom of the tube indicated biofilm formation. Ring formation at the liquid interface was not considered as an indication of biofilm production. The test was conducted in triplicate and results were expressed as negative - , weak + , moderate ++ and strong +++ as described by Gokce et al., $2007{ }^{(19)}$. Staphylococcus epidermidis ATCC 35984 and C. albicans ATCC 10231 were used as positive and negative controls respectively.

Candida ATCC control strains were obtained from Microbiologics Inc, USA.

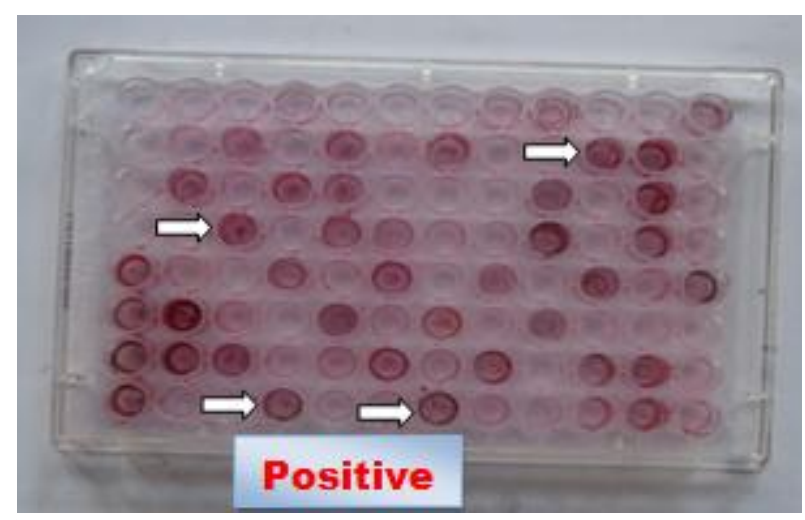

Figure 1: Biofilm formation by Candida species (Microtitre plate method)

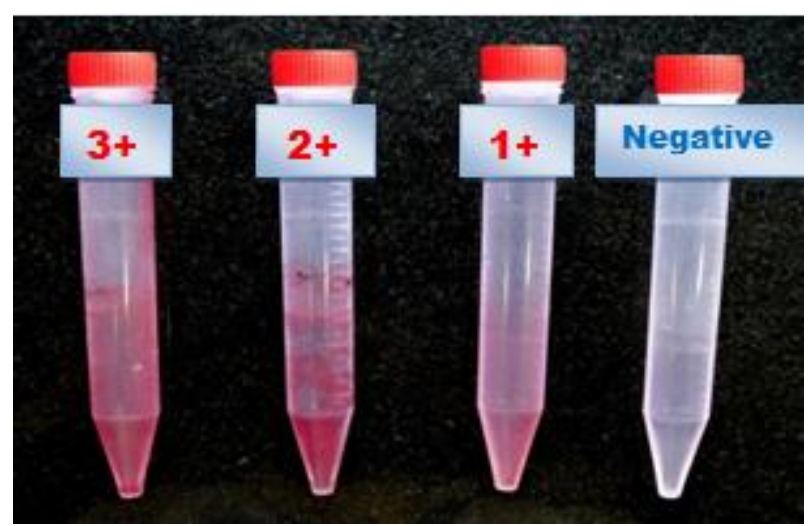

Figure 2: Biofilm formation by Candida species (Tube method)

\section{Results}

A total 100 specimens showing culture positive for Candida were taken for the study. Out of these 100 Candida strains isolated, 44 (44\%) were identified as Candida albicans and $56(56 \%)$ were identified as Non-albicans Candida species. These 100 isolates were studied for biofilm production. Out of total 100 Candida species studied, biofilm production was seen in 58/100 (58\%) isolates by microtitre plate method as shown in (Table 1).

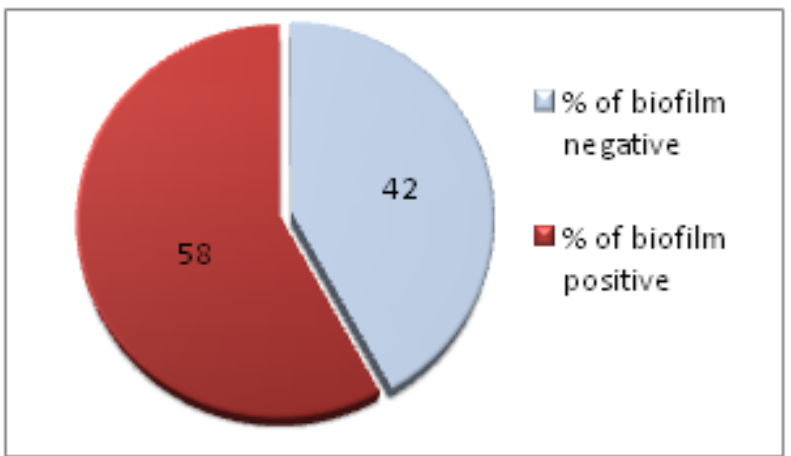

Figure 3: Biofilm formation by Candida species in Clinical specimens 


\section{International Journal of Science and Research (IJSR) \\ ISSN (Online): 2319-7064}

Index Copernicus Value (2013): 6.14 | Impact Factor (2015): 6.391

Table 1: Biofilm formation by various Candida spp.

\begin{tabular}{|c|l|c|c|c|c|c|c|}
\hline \multirow{2}{*}{ S.N } & \multirow{2}{*}{ Candida spp. } & \multicolumn{7}{|c|}{ No. of biofilm positive } \\
\cline { 2 - 8 } & $\mathbf{1 +}$ & $\mathbf{2 +}$ & $\mathbf{3 +}$ & $\mathbf{4 +}$ & Total & Percentages \\
\hline 1 & C. albicans $(\mathrm{n}=44)$ & 4 & 6 & 6 & 7 & 23 & $52.3 \%$ \\
\hline 2 & C. tropicalis $(\mathrm{n}=30)$ & 2 & 2 & 5 & 9 & 18 & $60.0 \%$ \\
\hline 3 & C. glabrata $(\mathrm{n}=15)$ & 1 & 2 & 2 & 5 & 10 & $66.7 \%$ \\
\hline 4 & C. krusei $(\mathrm{n}=7)$ & 0 & 1 & 2 & 3 & 6 & $85.7 \%$ \\
\hline 5 & C. gulliermondii $(\mathrm{n}=4)$ & 1 & 0 & 0 & 0 & 1 & $25.0 \%$ \\
\hline \multicolumn{2}{|}{ Total $(\mathrm{N}=100)$} & 8 & 11 & 15 & 24 & 58 & $58.0 \%$ \\
& & $(13.8 \%)$ & $(19 \%)$ & $(25.9 \%)$ & $(41.4 \%)$ & & \\
\hline
\end{tabular}

Chi-square $=8.493 ; \mathrm{df}=3 ; \mathrm{P}$-value $=0.0368 ;($ significant at $\mathrm{P}<0.05)$

Table 2: Biofilm production among Candida species.

\begin{tabular}{|c|c|c|c|}
\hline No. of isolates tested for biofilm & No. \& \% of biofilm Producers & $\begin{array}{c}\text { No. \& \% of } \\
\text { C. albicans producing biofilm }\end{array}$ & $\begin{array}{c}\text { No. \& \% of } \\
\text { NAC producing biofilm }\end{array}$ \\
\hline 100 & $58(58 \%)$ & $23(52.3 \%)$ & $35(62.5 \%)$ \\
\hline
\end{tabular}

Out of 44 Candida albicans isolated 23 (52.3\%) were biofilm producers. Among the 56 Non-albicans Candida species isolated, $35(62.5 \%)$ were biofilm producers. Among the 29 Non albicans Candida species isolated, biofilm production was seen predominantly in C. krusei $85.7 \%$ followed by C. glabrata $64.7 \%$ and C. tropicalis $60 \%$ as shown in Table 1. This shows biofilm formation is higher in Non-albicans candida than Candida albicans.

Table 3: Biofilm formation in various clinical samples:

\begin{tabular}{|c|c|c|c|c|c|c|}
\hline \multirow{2}{*}{ S.N } & Samples \& (No. of Candida spp.) & \multicolumn{5}{|c|}{ No. of biofilm positive } \\
\cline { 2 - 7 } & & $\mathbf{1 +}$ & $\mathbf{2 +}$ & $\mathbf{3 +}$ & $\mathbf{4 +}$ & Total (\%) \\
\hline 1 & Urine (n=30) & 2 & 5 & 6 & 8 & $21(70 \%)$ \\
\hline 2 & Pus (n=3) & 0 & 1 & 0 & 0 & $1(33.3 \%)$ \\
\hline 3 & Sputum (n=25) & 2 & 3 & 3 & 7 & $15(60 \%)$ \\
\hline 4 & Stool (n=10) & 1 & 0 & 2 & 3 & $6(60 \%)$ \\
\hline 5 & Vaginal swab (n=11) & 2 & 1 & 2 & 3 & $8(72.7 \%)$ \\
\hline 6 & Throat swab (n=6) & 0 & 1 & 1 & 1 & $3(50 \%)$ \\
\hline 7 & Skin scraping (n=5) & 0 & 1 & 0 & 0 & $1(20 \%)$ \\
\hline 8 & Nail clipping (n=3) & 1 & 0 & 0 & 0 & $0(0 \%)$ \\
\hline 9 & Endotracheal tube (n=2) & 0 & 0 & 1 & 0 & $1(50 \%)$ \\
\hline 10 & Ear swabs (n=2) & 1 & 0 & 0 & 0 & $1(50 \%)$ \\
\hline 11 & Eye swabs (n=3) & 9 & 12 & 15 & 22 & $1(50 \%)$ \\
\hline \multicolumn{2}{|c|}{ Total (n=100) } \\
\hline
\end{tabular}

Maximum Biofilm formation was seen in High vaginal swabs $(72.7 \%)$ followed by urine sputum, stool, throat swabs, ET, ear swabs, pus, eye swabs, skin scrapings \& nail clippings sample. While comparing tube method of biofilm production with microtitre plate method, microtitre plate method detected 5 more biofilm producers than tube method.

\section{Discussion}

Biofilms are notoriously difficult to eliminate and are a source of many recalcitrant infections. Although, bacterial biofilms and their role in disease have been investigated in detail over a number of years, much less is known about fungal biofilms. Present study was carried out in Department of Microbiology with aim to study the biofilm production by various Candida species isolated from different clinical samples at a tertiary care hospital of Navi Mumbai, India.

It is increasingly obvious that infections caused by Candida species are an escalating clinical problem, and with a limited arsenal of antifungal and a growing menace of biofilms, a lot has to be done for proper disease management. In the present study, biofilm production was found to occur most frequently in Non-albicans candida than C. albicans. This finding is in contrast to an earlier report that suggested that pathogenic Non-albicans candida were more likely to produce biofilms than $C$. albicans.

In our study, biofilm production was seen in $58 \%$ of Candida isolates which is close to the findings of S. Golia et al. ${ }^{(20)}$, Mythreyl SR. et al. ${ }^{(21)}$, Melek Inci et al. ${ }^{(22)}$, Nisha VJ et al. ${ }^{(23)}$, Sahar Ali M et al. ${ }^{(24)}$, Saurabh M et al. ${ }^{(25)} \&$ Arine Bruder et al. ${ }^{(26)}$ However lower percentage and higher percentage of biofilm production by Candida is shown by some researchers. In our study we found $52.3 \%$ of $C$. albicans were biofilm producers which correlate well with the findings of Melek Inci et al. ${ }^{(22)}$, Nisha VJ et al. ${ }^{(23)}$, Sahar Ali $\mathrm{M}$ et al. ${ }^{(24)}$, Saurabh M et al. ${ }^{(25)} \&$ Vinitha Mohandas et al. ${ }^{(27)}$ Similarly, $62.5 \%$ of Non-albicans candida were biofilm producers which is close to the findings of S. Golia et al. ${ }^{(20)}$, Mythreyl SR. et al. ${ }^{(21)} \&$ Sahar Ali M et al. ${ }^{(24)}$ In our study we found that NAC was more biofilm produces as compared to $\mathrm{C}$. albicans.

In our study, among the five Candida species which were most commonly isolated from clinical specimens $(C$.

\section{Volume 5 Issue 6, June 2016 www.ijsr.net}




\section{International Journal of Science and Research (IJSR) \\ ISSN (Online): 2319-7064}

Index Copernicus Value (2013): 6.14 | Impact Factor (2015): 6.391

albicans 44\%, C. tropicalis 30\%, C glabrata 15\%, C krusei $7 \%$ and $C$. guillermondii $4 \%$ ), biofilm production was most frequently observed for the isolates of C. krusei $85.7 \%$ followed by $C$. glabrata $(64.7 \%)$, C. tropicalis $(60 \%), C$. albicans $(52.3 \%)$ and $C$. guillermondii (25\%). In our study, C. krusei isolates were high biofilm production $85.7 \%, \mathrm{~S}$. Golia et al. ${ }^{(20)}$ and Vinitha Mohandas et al. ${ }^{(27)}$ also reported maximum biofilm production by $C$. krusei. In our study, $C$. glabrata isolates showed $64.7 \%$ biofilm production which is close to the finding of Alessandra R et al. ${ }^{(28)}$ In our study, $C$. tropicalis isolates showed $60 \%$ biofilm production which is close to the finding of Vivek A et al. ${ }^{(29)}$ In our study, $C$. guillermondii showed (25\%) biofilm production which is close to the finding of Rahul P Dahale et al. ${ }^{(30)}$ In our study, biofilm production was most frequently seen in vaginal swabs $(72.7 \%)$ followed by urine $(70 \%)$, sputum $(60 \%)$, stool $(60 \%)$, throat swabs $(50 \%)$, endotracheal tube $(50 \%)$, ear swabs $(50 \%)$, pus $(33.3 \%)$, eye swabs $(33.3 \%)$ and skin scrapings $(20 \%)$.

Different authors had reported different percentage of Candida biofilm in various clinical samples. Our study shows $70 \%$ of Candida isolated from urine were biofilm producers which is close to the findings of Sachin C.D. et al.(31), Vivek A et al. ${ }^{(29)}$, Nisha VJ et al. ${ }^{(23)} \&$ Sahar Ali M et al. ${ }^{(24)} 60 \%$ of Candida isolated from sputum were biofilm producers which is close to the findings of Nisha VJ et al. ${ }^{(23)}$ \& Sahar Ali M et al. ${ }^{(24)} 72.7 \%$ of Candida isolated from vaginal swabs were biofilm producers which is close to the findings of Vivek A et al. ${ }^{(29)}$, Nisha VJ et al. ${ }^{(23)} \& \mathrm{~S}$. Golia et al. $^{(20)}$.

\section{Conclusion}

For the detection of biofilm production, we can conclude that, microtitre plate assay is seen to be the most sensitive, most reproducible, accurate, efficient and specific method to detect the biofilm production as compared to tube method/visual detection assay. To conclude, genus Candida has certain species which have the capability to produce high grade of biofilm and others which produce low grade of biofilms. It has been seen that organism in biofilm are more notorious to treat than their free or planktonic form, so, it is essential to prevent biofilm formation for easy treatment and improving mortality and morbidity rate.

\section{Acknowledgements}

We want to thank the Dean Dr. G.S. Narshetty (Mahatma Gandhi Mission's Medical College, Navi Mumbai) and Medical Superintendent Dr. Prakash P. Doke (Mahatma Gandhi Misson's Hospital Kamothe, Navi Mumbai) for their support and permission. Also thanks to my HOD Dr. A.D. Urhekar and all staff of Microbiology Department, MGM Medical College, Navi Mumbai for their valuable suggestion and support.

\section{References}

[1] Silva S, Negri M, Henriques M, Oliveira R, Williams DW, Azeredo J. Adherence and biofilm formation of
non-Candida albicans Candida species. Trends Microbiol. 2011; 19(5):241-7.

[2] DiDone L, Oga D, Krysan DJ. A novel assay of biofilm antifungal activity reveals that amphotericin B and caspofungin lyse Candida albicans cells in biofilms. Yeast. 2011; 28(8):561-8.

[3] Hahnel S, Rosentritt M, Burgers R, Handel G, Lang R. Candida albicans biofilm formation on soft denture liners and efficacy of cleaning protocols. Gerodontology. 2012; 29(2):e383-91.

[4] LaFleur MD, Lucumi E, Napper AD, Diamond SL, Lewis K. Novel high-throughput screen against Candida albicans identifies antifungal potentiators and agents effective against biofilms. $J$ Antimicrob Chemother. 2011; 66(4):820-6.

[5] Punithavathy PM, Nalina K, Menon T. Antifungal susceptibility testing of Candida tropicalis biofilms against fluconazole using calorimetric indicator resazurin. Indian J Pathol Microbiol. 2012; 55(1):72-4.

[6] Yang YL, Cheng HH, Ho YA, Hsiao CF, Lo HJ. Fluconazole resistance rate of Candida species from different regions and hospital types in Taiwan. $J$ Microbiol Immunol Infect. 2003; 36(3):187-91.

[7] Calderone RA, Fonzi WA. Virulence factors of Candida albicans. Trends Microbiol. 2001;9(7):327-35.

[8] Gokce G, Cerikcioglu N, Yagci A. Acid proteinase, phospholipase, and biofilm production of Candida species isolated from blood cultures. Mycopathologia. 2007;164(6):265-9.

[9] Paul N, Mathai E, Abraham OC, Michael JS, Mathai D. Factors associated with candiduria and related mortality. J Infect. 2007;55(5):450-5.

[10] Konopka K, Dorocka-Bobkowska B, Gebremedhin S, Duzgunes N. Susceptibility of Candida biofilms to histatin 5 and fluconazole. Antonie Van Leeuwenhoek. 2010;97(4):413-7.

[11] Khan MS, Ahmad I. Antibiofilm activity of certain phytocompounds and their synergy with fluconazole against Candida albicans biofilms. J Antimicrob Chemother. 2012;67(3):618-21.

[12] Jain N, Kohli R, Cook E, Gialanella P, Chang T, Fries BC. Biofilm formation by and antifungal susceptibility of Candida isolates from urine. Appl Environ Microbiol. 2007;73(6):1697-703.

[13] Mohammadi P, Shoaie N, Roudbar Mohammadi S. Isolation and Detection of Yeast Biofilms From Urine Catheters of Infectious Patients. Jundishapur $J$ Microbiol. 2012;5(4):533-6.

[14] Tobudic S, Kratzer C, Lassnigg A, Presterl E. Antifungal susceptibility of Candida albicans in biofilms. Mycoses. 2012;55(3):199-204.

[15]Tsang CS, Ng H, McMillan AS. Antifungal susceptibility of Candida albicans biofilms on titanium discs with different surface roughness. Clin Oral Investig. 2007;11(4):361-8.

[16] Chander J. Candidiasis. Section V, Chapter 20. Textbook of Medical Mycology. $3^{\text {rd }}$ edition. New Delhi: Mehta Publisher; 2009. Page no. 274-282.

[17] Nimet Yigit, Esin Aktas, Saadettin Dagistan, Ahmet Ayyildiz. Investigating Biofilm Production, Coagulase and Hemolytic Activity in Candida Species Isolated From Denture Stomatitis Patients. EAJM 2011; 43: 2732.

Volume 5 Issue 6, June 2016 www.ijsr.net

Licensed Under Creative Commons Attribution CC BY 


\section{International Journal of Science and Research (IJSR) \\ ISSN (Online): 2319-7064}

Index Copernicus Value (2013): 6.14 | Impact Factor (2015): 6.391

[18] Christensen GD, Simpson WA, Younger JJ, Baddour LM, Barrett FF, Melton DM, et al. Adherence of coagulase-negative staphylococci to plastic tissue culture plates: a quantitative model for the adherence of staphylococci to medical devices. J Clin Microbiol. 1985; 22:996-1006.

[19] Gokce G, Cerikcioglu N, Yagci A. Acid proteinase, phospholipase, and biofilm production of Candida species isolated from blood cultures. Mycopathologia 2007; 164:265-9.

[20] Saroj Golia, Vivek Hittinahalli, Sangeetha K. T, Vasudha C. L. Study of biofilm formation as a virulence marker in Candida species isolated from various clinical specimens. Journal of Evolution of Medical and Dental Sciences/Volume 1/Issue 6/December-2012 Page-12381246.

[21] Mythreyi Shekar Rishpana, Jyoti S Kabbin. Candiduria in Catheter Associated Urinary Tract Infection with Special Reference to Biofilm Production. Journal of Clinical and Diagnostic Research. 2015 Oct, Vol-9(10): DC11-DC13.

[22] Melek Inci, Mustafa Altay Atalay, Ayse Nedret Koc , Erkan Yula, Omer Evirgen, Suleyman Durmaz et al. Investigating virulence factors of clinical Candida isolates in relation to atmospheric conditions and genotype. Turk J Med Sci 2012; 42 ((Sup.2): 14761483.

[23] Nisha VJ, Mudhigeti N, Asir J, Chandrakesan SD. Detection of virulence factors and phenotypic characterization of Candida isolates from clinical specimens. J Curr Res Sci Med 2015; 1:27-31.

[24] Sahar Ali Mohamed and Ziab Zakey Al-Ahmadey. Biofilm Formation and Antifungal Susceptibility of Candida Isolates from Various Clinical Specimens. British Microbiology Research Journal 3(4): 590-601, 2013.

[25] Saurabh Muni, Sarala Menon, Chhaya Chande, Aruna Gohil, Abhay Chowdhary, Ameeta Joshi. Candida biofilm. Bombay Hospital Journal, Vol. 54, No. 1, 2012.

[26] Ariane Bruder-Nascimento, Carlos Henrique Camargo, Alessandro Lia Mondelli, Maria Fatima Sugizaki, Terue Sadatsune, Eduardo Bagagli. Candida species biofilm and Candida albicans ALS3 polymorphisms in clinical isolates. Brazilian Journal of Microbiology 45, 4, 13711377 (2014).

[27] Mohandas V, Ballal M. Distribution of Candida Species in different clinical samples and their virulence: Biofilm formation, proteinase and phospholipase production: A study on hospitalized patients in Southern India. J Global Infect Dis 2011;3:4-8.

[28] Alessandra Ribeiro de Freitas, Lilian Cristiane Baeza, Maria Graciela Iecher Faria, Kelen Fátima Dalben Dota, Patricio Godoy Martínez, Terezinha Inez Estivalet Svidzinski. Yeasts isolated from nosocomial urinary infections: Antifungal susceptibility and biofilm production. Rev Iberoam Micol. 2014; 31(2):104-108.

[29] Vivek Agwan, Ruchika Butola, Molly Madan. Comparison of biofilm formation in clinical isolates of Candida species in a tertiary care center, North India. Indian J Pathol Microbiol 2015;58:475-8.

[30] Rahul P. Dhale, M. V. Ghorpade, C. A. Dharmadhikari. A Study of Biofilm Production and Antifungal Susceptibility of Clinical Isolates of Candida Species.
International Journal of Health Sciences \& Research Vol.4; Issue: 11; November 2014.

[31] Sachin C Deorukhkar \& Santosh Saini. Non-albicans candida species: its isolation pattern, Species distribution, virulence factors and Antifungal susceptibility profile. International journal of medical science and public health. 2013; 2 (3): 533-538.

Volume 5 Issue 6, June 2016 www.ijsr.net 